\section{UV-C rays to simulate the exposition of photosynthetic organisms to solar radiation in space environments}

\author{
Adriano Sofo \\ Department of European and \\ Mediterranean Cultures: Architecture, \\ Environment and Cultural Heritage \\ (DiCEM), Università degli Studi della \\ Basilicata, Matera, Italy
}

\begin{abstract}
Ultraviolet (UV) is a component of the solar radiation with a wavelength in the range of $100 \leq \lambda \leq 390 \mathrm{~nm}$ that is almost entirely shielded by the terrestrial atmosphere, but not in space. The effects of UV-C $(100 \leq \lambda \leq 280 \mathrm{~nm})$ on plants mainly depend on: i) the applied UV-C radiation dose and quality, ii) the different plant species and varieties used, and iii) the phenological phase of irradiated plants. UV-C radiation can be extremely dangerous also at low exposition times. On the other side, considering that terrestrial plants under sunlight are naturally exposed to low doses of UV-C, the question is how much UV-C could be beneficial for plants cultivated in space, in relation to i) protection of plants from pathogens, ii) increase of the concentration of important dietary supplements, and iii) regulation of some physiological processes. The research on UV-C should be more addressed to better evaluate the damages and benefits in UV-C-exposed photosynthetic organisms, involving plants useful for Bioregenerative Life Support Systems (BLSSs).
\end{abstract}

\section{Introduction}

Ultraviolet (UV) is a component of the solar radiation with a wavelength in the range of $100 \leq \lambda \leq 390 \mathrm{~nm}$, where the UV$\mathrm{C}$ part is that with the lower wavelength $(100-280 \mathrm{~nm})$, or rather with the higher associated energy. ${ }^{1,2}$ The UV-C radiation is strongly absorbed by oxygen (100-200 nm) in the whole atmosphere and from the ozone layer (200-280) in the stratosphere (that starts at an altitude of around $12 \mathrm{~km}$ and ends at about $50 \mathrm{~km}$ ), so that the amount of UV-C reaching the Earth's surface, except for the peaks of the highest mountains, is extremely low but at the same time indispensable for some plant physiological processes (Figure 1). ${ }^{3}$

The UV-C radiation has a strong and effective germicidal action on microorganisms in water, on surfaces and in the air. ${ }^{2}$ High-energy UV-C radiation, due to the free radicals produced by its ionizing activity and to the fact that nucleotides, RNA, ssDNA, and dsDNA all have a peak of absorption centered at $260 \mathrm{~nm}$ (within the UV-C range), is responsible for molecular damages in many organisms. This is particularly true for all photosynthetic organisms, that have different types of photoreceptors and pigments that can be easily photo-oxidized by this radiation. ${ }^{4}$ Indeed, the exposition of plants to acute levels of UV-C radiation induces oxidative damage, genetic instability, DNA hypermethylation and genetic mutations, that in turn can have strong negative effects on plant growth, morphology, flowering, pollination, transpiration and photosynthesis. ${ }^{5-7}$ These genetic changes can even be transmitted epigenetically, ${ }^{4}$ and/or can eventually be repaired by specific proteins. ${ }^{8}$ At high irradiance levels (10 to $5 \mathrm{~kJ} \mathrm{~m}^{-2}$ ), UV-C rays can cause cell apoptosis and ultimately death. ${ }^{5,6}$ It is also true that the application of relatively low doses of UV-C radiation is often not lethal, as it leads to the activation of protective biochemical mechanisms, including increased synthesis of polyphenols, ${ }^{9}$ emission of volatiles compounds, ${ }^{7}$ and more generally higher levels of UV-C absorbing pigments. ${ }^{10}$

The increasing trend of UV-C flux on Earth's surface due to the depletion of the stratospheric ozone protective layer makes the study of the effect of UV-C radiation on plants extremely relevant and urgent. ${ }^{3}$ Indeed, if the atmospheric pollution due to chlorofluorocarbons and other halogenated compounds will continue at this rate, in a few decades Earth conditions will be hardly compatible with life. Right here lies the importance of UV-C radiation studies on plants, as the repercussion of these experiments, as often it happens with space research, have been and will be useful for plant crops on Earth's surface. From a spaceflight perspective, it is important to understand how photosynthetic organisms either experimentally placed outside the International Space Station (ISS) for simulating a complete solar radiation, or grown under environmental conditions resembling those of planetary bodies' surfaces - ${ }^{11}$ respond to UV-C radiation, in terms of stress resistance, growth, morphology and development.
Correspondence: Adriano Sofo, Department of European and Mediterranean Cultures: Architecture, Environment and Cultural Heritage (DiCEM), Università degli Studi della Basilicata, Via Lanera 20, I-75100, Matera, Italy.

E-mail: adriano.sofo@unibas.it

Key words: Bioregenerative Life Support Systems (BLSSs), Hydroponic, Solar radiation, Space environments, Ultraviolet-C radiation.

Acknowledgements: This article was supported by the JSPS Fellowship "Modification of secondary metabolism of edible rose petals by ultraviolet irradiation" (ID: S19029).

Conflict of interest: The author declares no potential conflict of interest.

Received for publication: 14 November 2019 Accepted for publication: 23 December 2019.

This work is licensed under a Creative Commons Attribution-NonCommercial 4.0 International License (CC BY-NC 4.0).

${ }^{(}{ }^{C}$ Copyright: the Author(s), 2020

Licensee PAGEPress srl, Italy

International Journal of Plant Biology 2020; 11:8379 doi:10.4081/pb.2020.8379

\section{Where $\mathrm{UV}-\mathrm{C}$ research has focused so far?}

The effects of UV-C on plants mainly depend on i) the applied UV-C radiation dose and quality (e.g., exposure durations and absorbance peaks of the incident spectra), ii) the different plant species and varieties used, and iii) the phenological phase of irradiated plants. ${ }^{3,4,12}$ In most articles dealing with UV-C-irradiated plants, the radiation exposure durations can vary from a few minutes to some hours, the applied average irradiance ranges from 2 to $500 \mathrm{~J} \mathrm{~m}^{-2}$. ${ }^{11} \mathrm{In}$ many articles, the distance and the incident angle of the plants from the light source, and the basic parameters of the growing chambers (e.g. temperature, humidity, photoperiod) are not specified. This makes often difficult to evaluate and normalize the different effects of UV-C radiation on plant metabolism, growth and reproduction.

The UV-C-related modifications at the physiological, cellular, biochemical and molecular levels have been mostly demonstrated in the model species Arabidopsis thaliana. $5,7,8,10$ The majority of the recent 
articles on UV-C radiation has been focused on the control of the pathogens of edible plants. ${ }^{13-15}$ Strictly related to pest control, many studies dealt with the pre-harvest application of UV-C radiation for improving the post-harvest quality, in terms of i) increased levels of health-promoting compounds, ${ }^{16-18}$ ii) enhancement of the enzymatic and non-enzymatic antioxidant capacity of UV-C-irradiated crops, ${ }^{19-21}$ and iii) higher product physical consistency. ${ }^{16,22}$ Finally, a few papers were focused on the positive and promoting effects of UV-C radiation on germination, sprouting, growth and flowering. ${ }^{23,24}$

According to two recent studies from our research group, ${ }^{25,26}$ wild plants (common dandelion and purple coneflower) seem to be more tolerant to UV-C radiation compared to cultivated ones (e.g., tomato), even if, at high exposure times $(30,60$ and $120 \mathrm{~min}$ with an irradiation of $3.8 \mathrm{~J} \mathrm{~m}^{-2}$ and plants at $1-\mathrm{m}$ distance from the UV-C source), significantly short-term and longterm (up to 120 days) negative effects have been observed for gas exchange, chlorophyll content and fresh weight in all the species examined.

\section{UV-C and plants in space: A dis- cussion}

From a spaceflight perspective, it is important to understand how photosynthetic organisms - either experimentally placed outside the International Space Station (ISS) for simulating a complete solar radiation, ${ }^{27,28}$ or grown under environmental conditions resembling those of planetary bodies' surfaces $-{ }^{11,29,30}$ respond to UV-C radiation, in terms of stress resistance, growth, morphology and development.

The potential of photosynthetic organisms in long-distance space travel or extraplanetary habitation could be relevant for regenerating molecular oxygen, cleaning water and providing food useful to the astronauts, ${ }^{30}$ that is for their bioregenerative services. Unfortunately, as Barker and Gilroy pointed out, ${ }^{12}$ Life in space isn't easy, even if you are green, especially because radiation damage can severely impede a sustained presence of terrestrial organisms away from their evolutionary home. In space, photosynthetic organisms must face a multiple-stress environment that negatively affects many of their physiological functions, but the high radiation level remains one of the most difficult obstacles to overcome. ${ }^{30}$ It is always necessary to keep in mind that UV-C radiation can be extremely dangerous also at low exposition times (few minutes). ${ }^{25,26}$ For this reason, in space environments, UV-C radiation should be adequately shielded and plant exposure times should be properly chosen.

On the other side, considering that terrestrial plants under sunlight are naturally exposed to low doses of UV-C from sunlight, several ideas have been proposed to direct solar radiation for maintaining plant growth on the Lunar or Mars surface. The question is how much UV-C could be beneficial for plants cultivated in space. Indeed, it is necessary to expose plants to low doses of UV-C radiation for three practical purposes: i) protecting plants from pathogens, ii) increasing the concentration of important dietary supplements needful for astronauts, and iii) regulating some physiological processes, such as germination, sprouting and flowering.

Regarding the first point, one could say that many pathogens are absent in the space environment, but it has been recently found that plants host many microorganisms inside their tissues - including seed - as endophytes. ${ }^{31}$ So, pathogens do not necessarily have to come from the outside. About the point two, recent studies have elucidated that edible plants irradiated with UV-C show an increased biosynthesis of secondary metabolites, protective against highenergy radiation, such as vitamin $\mathrm{E}$, carotenoids (e.g., lycopene, $\beta$-carotene and lutein), flavonoids (e.g., anthocyanins, quercetin and kaempferol derivatives), and

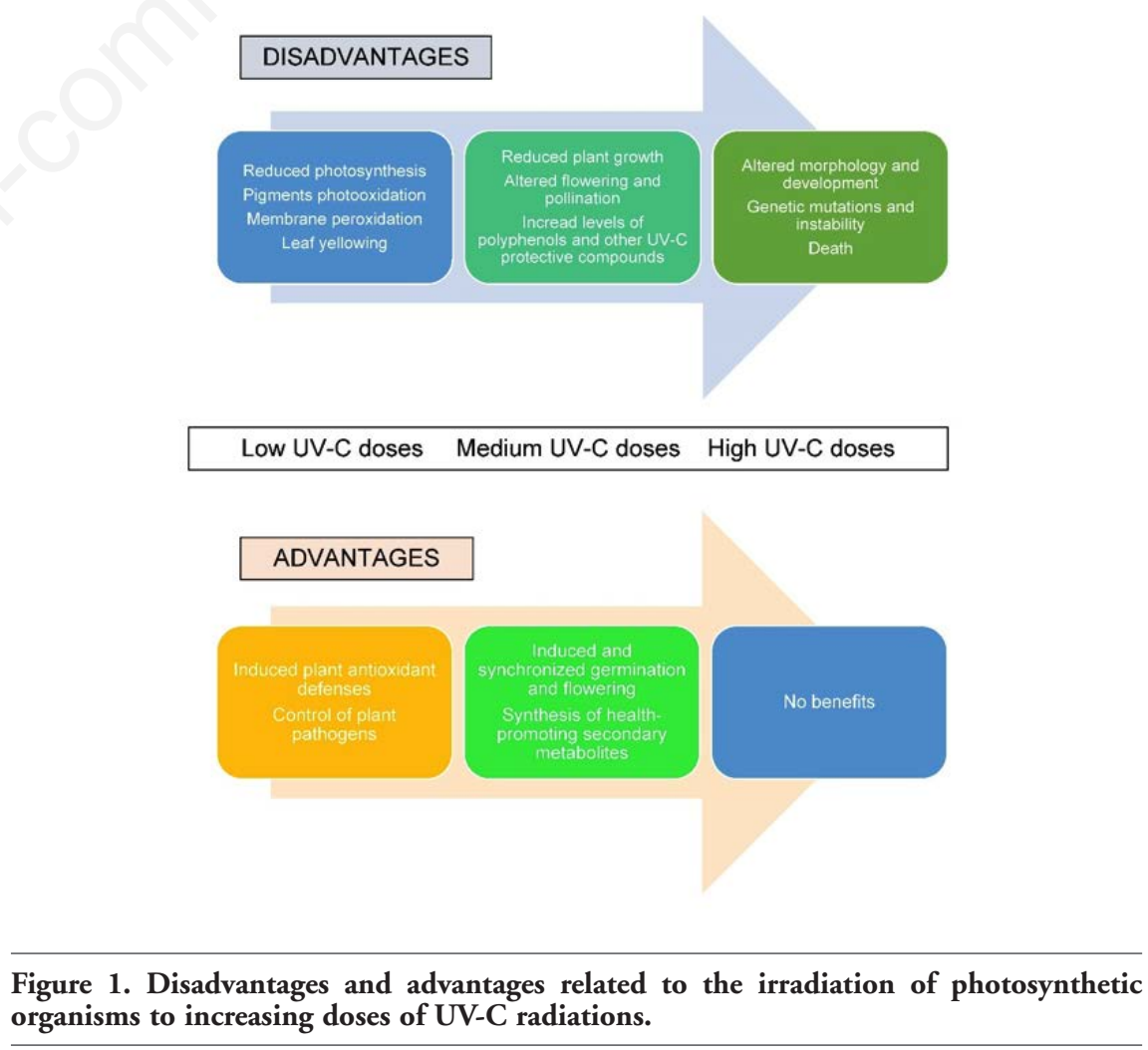

Low UV-C doses Medium UV-C doses High UV-C doses

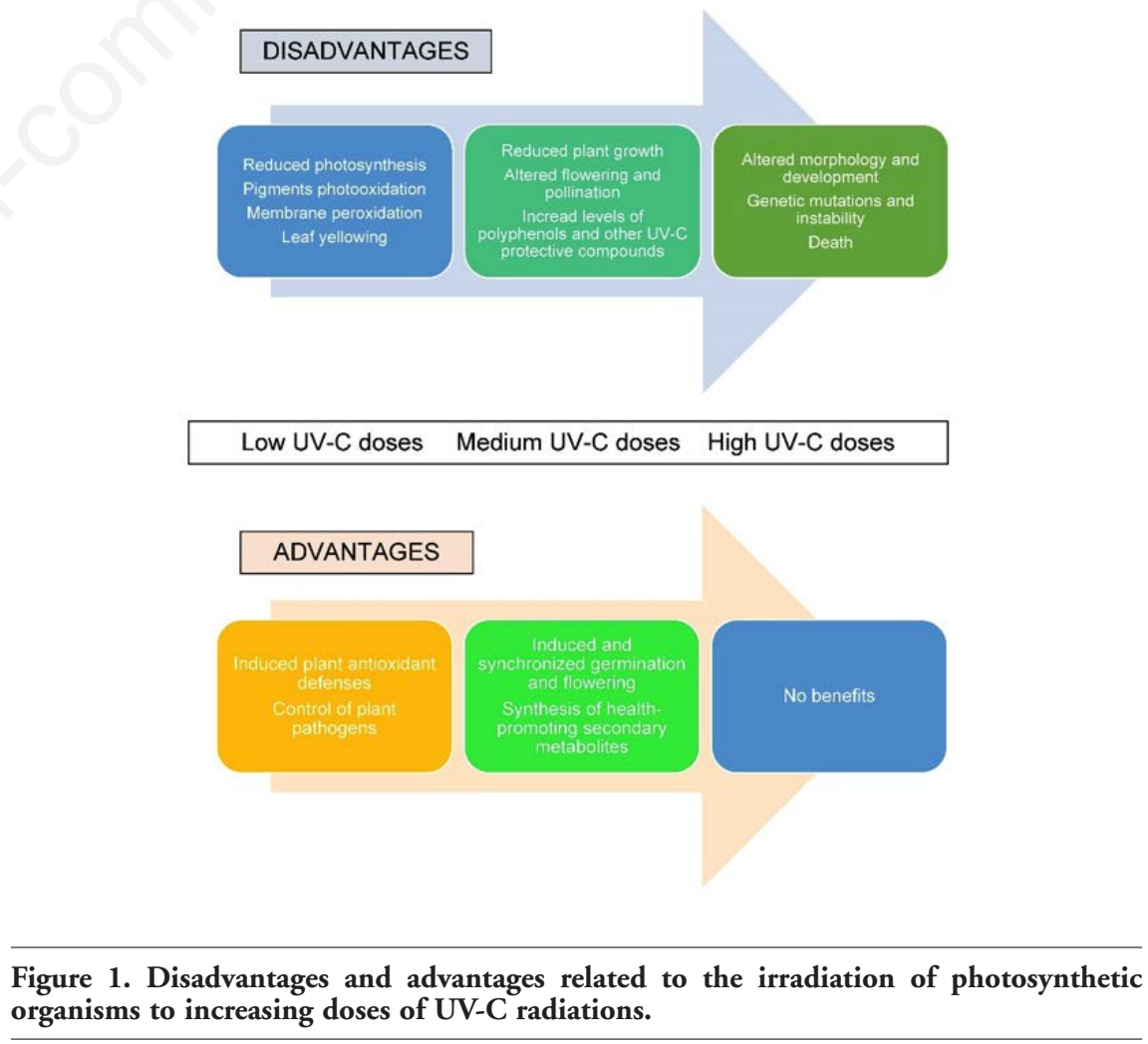

Figure 1. Disadvantages and advantages related to the irradiation of photosynthetic organisms to increasing doses of UV-C radiations.

phenolic acids (e.g. ferulic, coumaric and caffeic acid derivatives), partly due to the UV-C-induced up-regulation of the genes encoding for their biosynthetic enzymes. ${ }^{16-}$ ${ }^{18}$ Finally, the priming effect of UV-C radiation on germination, sprouting and flowering, as recently observed by some authors, ${ }^{23,24}$ could be of paramount importance for growing plants in space, allowing to synchronize these important plant phenological phases.

So, why conducting studies on UV-C radiation is essential for the extraterrestrial cultivation of plants? Firstly, UV-C is the most harmful and ionizing of the solar radiations and can seriously damage plants in space environments, where solar rays are not filtered by any (e.g., Moon) or very rarefied (e.g., Mars) atmosphere. Secondly, UV-C studies have been mainly focused on contrasting different plant pests and on ameliorating the quality of vegetables and fruit, but much less on the physiology and biochemistry of UV-C irradiated cyanobacteria and algae.

This latter, due to the possibility of easily growing them in small spaces and in hydroponic conditions, could be a good choice for providing the bioregenerative services necessary for the permanent and sustainable extraterrestrial habitation of humans. First of all, cyanobacteria generally resulted to have a higher degree tolerance to UV-C radiation due to their evolutionary history, as they originated in an atmosphere without ozone. Indeed, the threshold of UV- 
$\mathrm{C}$ radiation at which cyanobacteria can survive, but algae cannot, was found to be approximately $0.09 \mathrm{~W} \mathrm{~m}^{-2} .32$ Algae are more prone to UV-induced chlorophyll photooxidation, that causes decreases in net photosynthetic rates and chlorophyll efficiency measured by chlorophyll fluorescence. Unfortunately, this clear and logical trend has some exceptions. In two articles of Tao et al., ${ }^{33,34} \mathrm{UV}-\mathrm{C}$ irradiation at 20-200 $\mathrm{mJ} \mathrm{cm} \mathrm{cm}^{-2}$ (particularly $>50 \mathrm{~mJ} \mathrm{~cm}$ cm $^{-2}$ appeared to be deleterious for the toxic cyanobacterium Microcystis aeruginosa while neither significant suppression nor disintegration effects on green algae were observed. The same results on Microcystis aeruginosa have been confirmed by $\mathrm{Ou}$ et al. ${ }^{35}$ Instead, UV-C radiation at very high doses $\left(150-300 \mathrm{~kJ} \mathrm{~m}^{-2}\right)$ result to be lethal for both cyanobacteria and algae. ${ }^{36,37,38}$

Thus, many questions and obstacles to overcome still remain. For answering and solving them, the research should be more addressed to better evaluate the damages at physiological, biochemical and molecular levels - occurring in UV-C-exposed photosynthetic organisms. Studies on UV-C should mainly involve plants useful for bioregenerative life support systems (BLSSs) and be focused on the physical and mental well-being of the astronauts, that only an environment rich of plants can guarantee. For all these reasons, my wish is to encourage young scientists and researchers to undertake studies in this challenging research area.

\section{References}

1. Stapleton AE. Ultraviolet radiation and plants: burning questions. Plant Cell 1992;4:1353-8.

2. Sofo A, Castronuovo, D, Lovelli S, et al. Growth patterns of tomato plants subjected to two non-conventional abiotic stresses: UV-C irradiations and electric fields. In: Ahmad P, Wani MR (eds.) Physiological mechanisms and adaptation strategies in plants under changing environment - Volume 2. New York, NY, USA: Springer; 2014. pp. 285-96.

3. Herndon JM, Hoisington RD, Whiteside M. Deadly ultraviolet UV-C and UV-B penetration to Earth's surface: human and environmental health implications. J Geog Environ Earth Sci Int 2018;14:1-11.

4. Müller-Xing R, Xing Q, Goodrich J. Footprints of the sun: memory of UV and light stress in plants. Front Plant Sci 2014;5:474.

5. Danon A, Gallois P. UV-C radiation induces apoptotic-like changes in Arabidopsis thaliana. FEBS Lett 1998;437:131-6.

6. Nawkar GM, Maibam P, Park JH, et al. UV-Induced cell death in plants. Int $\mathrm{J}$ Mol Sci 2013;14:1608-28.

7. Yao Y, Danna CH, Zemp FJ, et al. UV$\mathrm{C}$-irradiated Arabidopsis and tobacco emit volatiles that trigger genomic instability in neighboring plants. Plant Cell 2011;23:2842-52.

8. Schalk C, Cognat V, Graindorge S, et al. Small RNA-mediated repair of UVinduced DNA lesions by the DNA DAMAGE-BINDING PROTEIN 2 and ARGONAUTE 1. Proc Natl Acad Sci USA 2012; 114:E2965-74.

9. Kostyuk V, Potapovich A, Suhan T, et al. Plant polyphenols against UV-CInduced cellular death. Planta Med 2008;74:509-14.

10. Shinkle JR, Edwards MC, Koenig A, et al. Photomorphogenic regulation of increases in UV-absorbing pigments in cucumber (Cucumis sativus) and Arabidopsis thaliana seedlings induced by different UV-B and UV-C wavebands. Physiol Plant 2010;138:113-21.

11. Brandt A, Meeßen J, Jänicke RU, et al. Simulated space radiation: impact of four different types of high-dose ionizing radiation on the lichen Xanthoria elegans. Astrobiology 2017;17:136-44.

12. Barker R, Gilroy S. Life in space isn't easy, even if you are green. Biochemist 2017;39:10-3.

13. Scott G, Almasrahi A, Malekpoor Mansoorkhani F, et al. Hormetic UV-C seed treatments for the control of tomato diseases. Plant Pathol 2019; 68:7007.

14. Short BD, Janisiewicz W, Takeda F, Leskey TC. UV-C irradiation as a management tool for Tetranychus urticae on strawberries. Pest Manag Sci 2018;74:2419-23.

15. Martínez-Sánchez A, Guirao-Martínez J, Martínez JA, et al. Inducing fungal resistance of spinach treated with preharvest hormetic doses of UV-C. LWT 2019;113:108302.

16. Wu J, Liu W, Yuan L, et al. The influence of postharvest UV-C treatment on anthocyanin biosynthesis in fresh-cut red cabbage. Sci Rep 2017;7:5232.

17. Gogo EO, Förster N, Dannehl D, et al. Postharvest UV-C application to improve health promoting secondary plant compound pattern in vegetable amaranth. Inn Food Sci Emerg Technol 2018;45:426-37.

18. Martínez-Sánchez A, Lozano-Pastor P, Artés-Hernández F, et al. Preharvest UV-C treatment improves the quality of spinach primary production and postharvest storage. Postharv Biol Technol 2019;155:130-9.

19. Andrade-Cuvi MJ, Moreno C, Zaro MJ, et al. Improvement of the antioxidant properties and postharvest life of three exotic Andean fruits by UV-C treatment. J Food Qual 2017:Article ID 4278795.

20. Li M, Li X, Han C, et al. UV-C treatment maintains quality and enhances antioxidant capacity of fresh-cut strawberries. Postharv Biol Technol 2019;156: 110945.

21. Luo YY, Li RX, Jiang QS, et al. Changes in the chlorophyll content of grape leaves could provide a physiological index for responses and adaptation to UV-C radiation. Nord J Bot 2019: e02314.

22. Ortiz Araquea LC, Ortiz CM, Darré M, et al. Role of UV-C irradiation scheme on cell wall disassembly and surface mechanical properties in strawberry fruit. Postharv Biol Technol 2019;150: 122-8.

23. Darras AI, Vlachodimitropoulou A, Dimitriadis C. Regulation of corm sprouting, growth and flowering of pot Freesia hybrida L. plants by cold and UV-C irradiation forcing. Sci Hort 2019;252:110-2.

24. Sadeghianfar P, Nazari M, Backes G. Exposure to ultraviolet (UV-C) radiation increases germination rate of maize (Zea maize L.) and sugar beet (Beta vulgaris) seeds. Plants (Basel) 2019;8:E49.

25. Castronuovo D, Sofo A, Lovelli S, et al. Effects of UV-C radiation on common dandelion and purple coneflower: First results. Int J Plant Biol 2017;8:61-4.

26. Castronuovo D, Tataranni G, Lovelli S, et al. UV-C irradiation effects on young tomato plants: first results. Pak J Bot 2014;46:945-9.

27. Tepfer D, Leach S. Survival and DNA damage in plant seeds exposed for 558 and 682 days outside the International Space Station. Astrobiology 2017;17:205-15.

28. Backhaus T, Meeßen J, Demets R, et al. Characterization of viability of the lichen Buellia frigida after 1.5 years in space on the International Space Station. Astrobiology 2019;19:233-41.

29. Kranz AR. Genetic and physiological damage induced by cosmic radiation on dry plant seeds during space flight. Adv Space Res 1986;6:135-8.

30. Vandenbrink JP, Kiss JZ. Space, the final frontier: A critical review of recent experiments performed in microgravity. Plant Sci 2016;243:115-119.

31. Wheeler DL, Dung JKS, Johnson DA. 
From pathogen to endophyte: an endophytic population of Verticillium dahliae evolved from a sympatric pathogenic population. New Phytol 2019;222:497510.

32. Gao Y, Cui Y, Xiong W, et al. Effect of UV-C on algal evolution and differences in growth rate, pigmentation and photosynthesis between prokaryotic and eukaryotic algae. Photochem Photobiol 2019;85:774-82.

33. Tao Y, Mao X, Hu J, et al. Mechanisms of photosynthetic inactivation on growth suppression of Microcystis aeruginosa under UV-C stress.
Chemosphere 2013;93:637-44.

34. Tao Y, Zhang Z, Au DWT, et al. The effects of sub-lethal UV-C irradiation on growth and cell integrity of cyanobacteria and green algae. Chemosphere 2010;78:541-7.

35. Ou H, Gao N, Deng Y, et al. Mechanistic studies of Microcystic aeruginosa inactivation and degradation by UV-C irradiation and chlorination with poly-synchronous analyses. Desalination 2011;272:107-19.

36. Borderie F, Alaoui-Sehmer L, Bousta F, et al. Cellular and molecular damage caused by high UV-C irradiation of the cave-harvested green alga Chlorella minutissima: Implications for cave management. Int Biodeter Biodegr 2014;93:118-30.

37. Sofo A, Ricciuti P, Fausto C, et al. The metabolic and genetic diversity of soil bacterial communities depends on the soil management system and $\mathrm{C} / \mathrm{N}$ dynamics: The case of sustainable and conventional olive groves. Appl Soil Ecol 2019;137:21-28.

38. Borderie F, Alaoui-Sehmer L, Naoufal $\mathrm{R}$, et al. UV-C irradiation as a tool to eradicate algae in caves. Int Biodeter Biodegr 2011;65:579-84. 